\title{
Grey Relational Bidirectional Projection Method for Multicriteria Decision Making with Hesitant Intuitionistic Fuzzy Linguistic Information
}

\author{
Yuqi Zang (D), Xiaodong Zhao, Shiyong Li $(\mathbb{D}$, and Adnan Nazir \\ School of Economics and Management, Yanshan University, Qinhuangdao 066004, China \\ Correspondence should be addressed to Shiyong Li; shiyongli@ysu.edu.cn
}

Received 6 December 2017; Accepted 28 February 2018; Published 4 April 2018

Academic Editor: Guillermo Cabrera-Guerrero

Copyright (c) 2018 Yuqi Zang et al. This is an open access article distributed under the Creative Commons Attribution License, which permits unrestricted use, distribution, and reproduction in any medium, provided the original work is properly cited.

We investigate a novel approach for multicriteria decision making (MCDM) with hesitant intuitionistic fuzzy linguistic information. To compare the hesitant intuitionistic fuzzy linguistic term sets (HIFLTSs), we propose a comparison method of HIFLTSs. A family of distance measures of HIFLTSs is developed. After that, we propose the grey relational bidirectional projection method based on the proposed comparison method and distance measures of IVHFLNs for dealing with MCDM problems. Furthermore, we establish a nonlinear optimization model to obtain the weight vector of criteria. Finally, an illustrative example is given to demonstrate the effectiveness and flexibility of the proposed approach.

\section{Introduction}

Since 1975, Zadeh [1] first proposed the fuzzy linguistic term set which can depict the qualitative fuzzy information. It has become the beginning of qualitative decision making research. Qualitative decision making has been widely concerned by scholars and successfully applied to many areas [210]. However, in many practical qualitative decision making cases, it is often difficult for decision makers to express preferences by using a single linguistic term. The hesitant fuzzy linguistic term set (HFLTS) was proposed by Rodriguez et al. [11], which permits decision makers to use several possible linguistic terms to express preferences. Because the hesitant fuzzy linguistic term set can adequately express vague and imprecise information, more close to the decision maker's qualitative thinking cognition, which is regarded as a powerful tool for dealing with qualitative decision making problems, scholars had an in-depth study of hesitant fuzzy linguistic term sets and made some improvements.

In the aspect of the comparison method, Rodriguez et al. [11] first proposed the possibility degree for comparing HFLTSs; the definition of the possibility degree is based on the interval value which is constructed by the HFLTSs' envelopes. Wei et al. [12] pointed out that Rodriguez et al's method may not accord with common sense, and they constructed the new suitable possibility degree formula of HFLTSs by using the possibility degree theory. Lee and Chen [13] noted that the Rodriguez et al.s and Wei et al's methods were defined by using the maximum and minimum operators, which can not rank the preference orders in some cases. Thus, they proposed a novel comparison method of HFLTSs based on the likelihood. Tian et al. [14] also from the perspective of the likelihood proposed a qualitative flexible multiple criteria method, which can measure the consistency and inconsistency of the preference order under the hesitant fuzzy linguistic environment.

As to the distance measure, Liao et al. [15] defined a family of basic distance measures of HFLTs, then they proposed the distance measures between two collections of HFLTs in continuous and discrete cases and applied the measure method to the evaluation of the quality of movies. Liao and $\mathrm{Xu}$ [16] proposed a series of cosine distance measures of HFLTs from the geometric point of view, then the proposed measures were applied to the selection of ERP systems. Wang et al. [17] presented the hesitant fuzzy linguistic Hausdorff distance measure, which is not necessary to add and rearrange any linguistic terms in HFLTs and applied the distance measure to 
the TOPSIS and TODIM methods. Wang et al. [18] proposed the Euclidean distance measure based on the function of the position index for HFLTSs. Meng and Chen [19] considered the ordered positions and the internal interactions, developed the generalized hesitant fuzzy linguistic 2-additive Choquet weighted distance measure and the generalized hesitant fuzzy linguistic 2-additive Shapley Choquet weighted distance measure, and then applied the proposed measure to evaluate investment.

There are also some extensions of classical MCDM methods. Liao and $\mathrm{Xu}$ [16] explored the TOPSIS and VIKOR methods based on the cosine distance measure for solving the hesitant fuzzy linguistic multicriteria decision making. Liao et al. [20] used the VIKOR method for solving the hesitant fuzzy linguistic multicriteria decision making in which the criteria conflict with each other. Wei et al. [21] considered the decision maker's psychological behavior in the MCDM and proposed a hesitant fuzzy linguistic TODIM method. They applied the proposed method to evaluate the telecommunications service providers. Wang et al. [18] proposed the ELECTRE I method to deal with the MCDM problems based on the distance measure for HFLTSs. Liao et al. [22] defined the correlation coefficient of HFLTSs, then the traditional Chinese medical diagnosis was given to illustrate the applicability of the proposed method. Lin et al. [23] derived a family of hesitant fuzzy linguistic aggregation operators and applied the proposed operators to multiattribute decision making. Farhadinia [24] solved the hesitant fuzzy linguistic multiple criteria decision making problems with completely unknown weights by entropy measure; Gou et al. [25] proposed a hesitant fuzzy linguistic alternative queuing method based on the entropy and cross-entropy measures for the hesitant fuzzy linguistic term sets and applied the proposed measure to the tertiary hospital management.

However, while using the hesitant fuzzy linguistic term sets, only the linguistic terms in the membership function are used to express the degree of certainty of the property, and the importance of the uncertainty is ignored. In this case, Beg and Rashid [26] proposed the hesitant intuitionistic fuzzy linguistic term sets (HIFLTSs) which take into account both membership and nonmembership. The hesitant intuitionistic fuzzy linguistic term sets can depict the hesitation more comprehensively when faced with qualitative decision making problems. They used the TOPSIS method to deal with the hesitant intuitionistic fuzzy linguistic multicriteria decision making problem. Liu et al. [27] extended the WA and OWA operators to the hesitant intuitionistic fuzzy linguistic environment and developed some hesitant intuitionistic fuzzy linguistic aggregation operators and applied the HIFLWA operator to the MCDM. Rashid et al. [28] constructed an ELECTRE-based outranking method to deal with MCDM. Faizi et al. [29] proposed an outranking method for hesitant intuitionistic fuzzy linguistic group decision making based on the support function, the risk function, and the credibility function.

As mentioned previously, since HIFLTS was proposed in 2014, the study of MCDM methods based on hesitant intuitionistic fuzzy linguistic information is still at the initial stage, only a few studies are involved, and there is still much work we need to do for improving the research. First of all, the possibility degree for comparing HIFLTSs has not been studied. With respect to the shortcomings of the existing possibility degree of HFLTSs [11-13], we propose an improved probability degree of HFLTSs, then on the basis of the above, we define the possibility degree of HIFLTSs. This is the first motivation of our work. Then, on the study of distance measure, Beg and Rashid [26] defined the distance measure of HIFLTS; however, the proposed distance measure was based on the envelope of HIFLTSs. If two HIFLTSs have the same envelope, they will obtain the same distance, which is unreasonable. Rashid et al. [28] only considered the case that the number of elements in the membership degree and nonmembership degree is equal. The distance measure should be improved to overcome the drawback of the existing distance measures. This is the second motivation of our work. In addition, there are many famous methods for solving the MCDM problems with hesitant fuzzy linguistic information or hesitant intuitionistic fuzzy linguistic information, but none of studies have used grey relational projection method to handle the MCDM problems with hesitant fuzzy linguistic information or hesitant intuitionistic fuzzy linguistic information. Grey relational projection technology is one of the effective methods to deal with MCDM problems [30-32]. We improved the traditional grey relational projection method and proposed the grey relational bidirectional projection method to deal with the MCDM problems under the hesitant intuitionistic fuzzy linguistic environment. This is the third motivation of our study.

The rest of this paper is organized as follows: In Section 2, we present some definitions of the LTSs, HFLTSs, and HIFLTSs. In Section 3, we propose the comparison method and the distance measures of HFLTSs. Section 4 denotes studying the hesitant intuitionistic fuzzy linguistic MCDM based on the grey relational bidirectional projection. In Section 5, we present a numerical example to demonstrate the effectiveness and practicality of the proposed method and also discuss the advantages of the proposed method. In Section 6, we briefly conclude the paper.

\section{Preliminaries}

2.1. Linguistic Term Sets. Let $S=\left\{s_{i} \mid i=0,1, \ldots, g\right\}$ be a finite linguistic term set with odd cardinality, where $s_{i}$ represents a possible value for a linguistic variable, and the following characteristics should be satisfied [33]:

(1) The set is ordered: $s_{\alpha} \geq s_{\beta} \Leftrightarrow \alpha \geq \beta$.

(2) There is a negation operator: $\operatorname{neg}\left(s_{\alpha}\right)=s_{g-\alpha}$.

(3) If $s_{\alpha}>s_{\beta}$, then $\max \left\{s_{\alpha}, s_{\beta}\right\}=s_{\alpha}, \min \left\{s_{\alpha}, s_{\beta}\right\}=s_{\beta}$.

\subsection{Hesitant Fuzzy Linguistic Term Sets}

Definition 1 (see [11]). Let $S=\left\{s_{0}, s_{1}, \ldots, s_{g}\right\}$ be a linguistic term set; let $H_{S}$ be an HFLTS which is an ordered finite subset of the consecutive linguistic terms of $S$. 
Definition 2 (see [11]). Let $S=\left\{s_{0}, s_{1}, \ldots, s_{g}\right\}$ be a linguistic term set, let $H_{S}$ be an HFLTS, and the operational laws are defined as

(1) the upper bound: $H_{S^{+}}=\max \left(s_{i}\right)=s_{j}, s_{i} \in H_{S}$ and $s_{i} \leq s_{j} \forall i$

(2) the lower bound: $H_{S^{-}}=\min \left(s_{i}\right)=s_{j}, s_{i} \in H_{S}$ and $s_{i} \leq s_{j} \forall i$

(3) the envelope: $\operatorname{env}\left(H_{S}\right)=\left[H_{S^{-}}, H_{S^{+}}\right]$;

(4) the complement: $H_{S}^{c}=S-H_{S}=\left\{s_{i}, s_{i} \in S\right.$ and $s_{i} \notin$ $\left.H_{S}\right\}$.

\subsection{Hesitant Intuitionistic Fuzzy Linguistic Term Sets}

Definition 3 (see [26]). Let $X$ be fixed; HIFLTSs on $X$ are functions $H(x)$ and $G(x)$ that when applied to $X$ return ordered finite subsets of the consecutive linguistic term set, $S=\left\{s_{0}, s_{1}, \ldots, s_{g}\right\}$; the mathematical symbol is defined as

$$
E_{S}=\left\{\left(x, H_{S}(x), G_{S}(x)\right) \mid x \in X\right\},
$$

where $H(x)$ and $G(x)$ are the subsets of the consecutive linguistic terms of $S$, denoting the possible membership degrees and nonmembership degrees of the element $x \in X$ to the set $E_{S}$, respectively, with the conditions: $\max \left(H_{S}(x)\right)+$ $\min \left(G_{S}(x)\right) \leq s_{g} ; \min \left(H_{S}(x)\right)+\max \left(G_{S}(x)\right) \leq s_{g}$.

For convenience, the pair $\left(H_{S}(x), G_{S}(x)\right)$ is called the hesitant intuitionistic fuzzy linguistic term element (HIFLTE), denoted as $\left(H_{S}, G_{S}\right)$.

Definition 4 (see [26]). Let $E_{S}=\left(H_{S}, G_{S}\right)$ be an HIFLTS; the upper bound and lower bound are defined as

$$
\begin{aligned}
& H_{S^{+}}=\max \left(s_{i}\right)=s_{j}, \quad s_{i} \in H_{S}, \quad s_{i} \leq s_{j} \forall i ; \\
& H_{S^{-}}=\min \left(s_{i}\right)=s_{j}, \quad s_{i} \in H_{S}, \quad s_{i} \geq s_{j} \forall i ; \\
& G_{S^{+}}=\max \left(s_{i}\right)=s_{j}, \quad s_{i} \in G_{S}, \quad s_{i} \leq s_{j} \forall i ; \\
& G_{S^{-}}=\min \left(s_{i}\right)=s_{j}, \quad s_{i} \in G_{S}, \quad s_{i} \geq s_{j} \forall i .
\end{aligned}
$$

Definition 5 (see [26]). The envelope of the HIFLTS, env $\left(E_{S}\right)$, is defined as

$$
\operatorname{env}\left(E_{S}\right)=\left\{\left[H_{S^{-}}, H_{S^{+}}\right],\left[G_{S^{-}}, G_{S^{+}}\right]\right\} .
$$

Definition 6. The complement of HIFLTS, $E_{S}$, is defined as

$$
\begin{aligned}
E_{S}^{c} & =\left\{\left(S-H_{S}\right),\left(S-G_{S}\right)\right\} \\
& =\left\{\left(s_{i}, s_{i} \in S, s_{i} \notin H_{S}\right),\left(s_{i}, s_{i} \in S, s_{i} \notin G_{S}\right)\right\} .
\end{aligned}
$$

\section{A Comparison Method and Distance Measures of HIFLTSs}

3.1. A Comparison Method of HIFLTSs. Possibility degree is one of the most appropriate comparison methods to rank the preference order of different arguments. We have already pointed out in Introduction that some scholars have studied the possibility formula of HFLTSs; however, they have the drawback that they cannot compare HFLTSs in some cases. For instance, when the hesitant fuzzy linguistic term sets reduce to only one element, the possibility formula denominator is zero by using Lee and Chen's method [13]; obviously, that is unreasonable. Wei et al's method [12] may be a complex formula, but they gave us a good inspiration to develop the possibility degree of HIFLTSs.

In this paper, we combine the ideas of methods in $[12,13]$ and propose the improved possibility formula of HFLTSs, which can rank the preference order more efficiently. The possibility degree formula of HFLTSs is given as

$$
\begin{aligned}
& P\left(H_{S}^{1} \geq H_{S}^{2}\right)=\max \{1 \\
& \left.\quad-\max \left(\frac{\operatorname{Ind}\left(H_{S}^{2+}\right)-\operatorname{Ind}\left(H_{S}^{1-}\right)+1}{\# H_{S}^{1}+\# H_{S}^{2}}, 0\right), 0\right\},
\end{aligned}
$$

where $\# H_{S}^{1}, \# H_{S}^{2}$ are the number of elements in $H_{S}^{1}, H_{S}^{2}$. Ind $\left(s_{i}\right)=i$ (it provides the index associated with the label).

As with the possibility degree axiom of the interval number, the possibility degree of $p\left(H_{S}^{1} \geq H_{S}^{2}\right)$ satisfies the following properties:

(1) $0 \leq p\left(H_{S}^{1} \geq H_{S}^{2}\right) \leq 1$;

(2) $p\left(H_{S}^{1} \geq H_{S}^{1}\right)=0.5$;

(3) if $H_{S}^{1} \geq H_{S}^{2}$, then $p\left(H_{S}^{1} \geq H_{S}^{2}\right)=1$;

$$
\text { if } H_{S}^{1} \leq H_{S}^{2} \text {, then } p\left(H_{S}^{1} \geq H_{S}^{2}\right)=0 \text {; }
$$

(4) $p\left(H_{S}^{1} \geq H_{S}^{2}\right)+p\left(H_{S}^{2} \geq H_{S}^{1}\right)=1$;

(5) if $H_{S}^{1}=H_{S}^{2}$, then $p\left(H_{S}^{1} \geq H_{S}^{2}\right)=p\left(H_{S}^{2} \geq H_{S}^{1}\right)=0.5$.

Similar to the definition of the possibility degree for HFLTS, we give the definition for HIFFLSs.

Definition 7. Let $S=\left\{s_{0}, s_{1}, \ldots, s_{g}\right\}$ be a linguistic term set, let $E_{S}^{1}=\left(H_{S}^{1}, G_{S}^{1}\right)$ and $E_{S}^{2}=\left(H_{S}^{2}, G_{S}^{2}\right)$ be two HIFLTSs on $S$, and the possibility degree of $p\left(E_{S}^{1} \geq E_{S}^{2}\right)$ is denoted as

$$
\begin{aligned}
p( & \left.E_{S}^{1} \geq E_{S}^{2}\right)=\frac{1}{2}\left(p\left(H_{S}^{1} \geq H_{S}^{2}\right)+p\left(G_{S}^{2} \geq G_{S}^{1}\right)\right) \\
& =\frac{1}{2}(\max \{1 \\
& \left.-\max \left(\frac{\operatorname{Ind}\left(H_{S}^{2+}\right)-\operatorname{Ind}\left(H_{S}^{1-}\right)+1}{\# H_{S}^{1}+\# H_{S}^{2}}, 0\right), 0\right\} \\
& +\max \{1 \\
& \left.\left.-\max \left(\frac{\operatorname{Ind}\left(G_{S}^{1+}\right)-\operatorname{Ind}\left(G_{S}^{2-}\right)+1}{\# G_{S}^{1}+\# G_{S}^{2}}, 0\right), 0\right\}\right),
\end{aligned}
$$


where $\# H_{S}^{1}, \# H_{S}^{2}$ are the number of elements in $H_{S}^{1}, H_{S}^{2}$ and $\# G_{S}^{1}, \# G_{S}^{2}$ are the number of elements in $G_{S}^{1}, G_{S}^{2}$, respectively. $\operatorname{Ind}\left(s_{i}\right)=i$ (it provides the index associated with the label).

The possibility degree of $p\left(E_{S}^{1} \geq E_{S}^{2}\right)$ satisfies the following properties:

(1) $0 \leq p\left(E_{S}^{1} \geq E_{S}^{2}\right) \leq 1$;

(2) $p\left(E_{S}^{1} \geq E_{S}^{1}\right)=0.5$;

(3) if $E_{S}^{1} \geq E_{S}^{2}$, then $p\left(E_{S}^{1} \geq E_{S}^{2}\right)=1$;

if $E_{S}^{1} \leq E_{S}^{2}$, then $p\left(E_{S}^{1} \geq E_{S}^{2}\right)=0$;

(4) $p\left(E_{S}^{1} \geq E_{S}^{2}\right)+p\left(E_{S}^{2} \geq E_{S}^{1}\right)=1$;

(5) if $E_{S}^{1}=E_{S}^{2}$, then $p\left(E_{S}^{1} \geq E_{S}^{2}\right)=p\left(E_{S}^{2} \geq E_{S}^{1}\right)=0.5$.

3.2. Distance Measure of HIFLTSs. Xu [34] first proposed the distance measure of the linguistic term sets as follows.

Definition 8 (see [34]). Let $S=\left\{s_{0}, s_{1}, \ldots, s_{g}\right\}$ be a linguistic term set, let $s_{\alpha}, s_{\beta}$ be two linguistic terms, and then the deviation degree between $s_{\alpha}$ and $s_{\beta}$ is

$$
d\left(s_{\alpha}, s_{\beta}\right)=\frac{\alpha-\beta}{g+1},
$$

where $g+1$ is the number of linguistic terms in the set $S$.

Motivated by the definition of the distance measure for LTSs, we define the distance measure of HIFLTSs $E_{S}^{1}=$ $\left(H_{S}^{1}, G_{S}^{1}\right)$ and $E_{S}^{2}=\left(H_{S}^{2}, G_{S}^{2}\right)$.

$$
\begin{aligned}
& E_{S}^{1}=\left(H_{S}^{1}, G_{S}^{1}\right)=\left(\bigcup_{\sigma_{l}^{1} \in H_{S}^{1}}\left\{s_{\sigma_{l}^{1}} \mid l=1, \ldots, \# H_{S}^{1}\right\},\right. \\
& \left.\bigcup_{\delta_{k}^{1} \in G_{S}^{1}}\left\{s_{\delta_{k}^{1}} \mid k=1, \ldots, \# G_{S}^{1}\right\}\right), \\
& E_{S}^{2}=\left(H_{S}^{2}, G_{S}^{2}\right)=\left(\bigcup_{\sigma_{l}^{2} \in H_{S}^{2}}\left\{s_{\sigma_{l}^{2}} \mid l=1, \ldots, \# H_{S}^{2}\right\},\right. \\
& \left.\bigcup_{\delta_{k}^{2} \in G_{S}^{2}}\left\{s_{\delta_{k}^{2}} \mid k=1, \ldots, \# G_{S}^{2}\right\}\right),
\end{aligned}
$$

where $\# H_{S}^{1}, \# H_{S}^{2}$ are the number of linguistic terms in $H_{S}^{1}$,

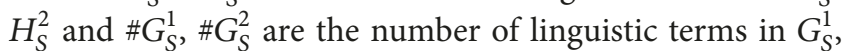
$G_{S}^{2}$, respectively. Where $\# H_{S}^{1}=\# H_{S}^{2}=L$ and $\# G_{S}^{1}=$ $\# G_{S}^{2}=K$, we need to make them equivalently by adding some linguistic terms to the shorter HIFLTS, according to the following principles: pessimistic principle, the lower bound will be added; optimistic principle, the upper bound will be added.

The distance measures for HIFLTSs $E_{S}^{1}=\left(H_{S}^{1}, G_{S}^{1}\right), E_{S}^{2}=$ $\left(H_{S}^{2}, G_{S}^{2}\right)$ are defined as follows.
The hesitant intuitionistic fuzzy linguistic Hamming distance is as follows:

$$
\begin{aligned}
& d_{\text {hiflhd }}\left(E_{S}^{1}, E_{S}^{2}\right) \\
& \quad=\frac{1}{2}\left(\frac{1}{L} \sum_{l=1}^{L} \frac{\left|\sigma_{l}^{1}-\sigma_{l}^{2}\right|}{g+1}+\frac{1}{K} \sum_{k=1}^{K} \frac{\left|\delta_{k}^{1}-\delta_{k}^{2}\right|}{g+1}\right) .
\end{aligned}
$$

The hesitant intuitionistic fuzzy linguistic Euclidean distance is as follows:

$$
\begin{gathered}
d_{\text {hifled }}\left(E_{S}^{1}, E_{S}^{2}\right)=\left(\frac { 1 } { 2 } \left(\frac{1}{L} \sum_{l=1}^{L}\left(\frac{\left|\sigma_{l}^{1}-\sigma_{l}^{2}\right|}{g+1}\right)^{2}\right.\right. \\
\left.\left.+\frac{1}{K} \sum_{k=1}^{K}\left(\frac{\left|\delta_{k}^{1}-\delta_{k}^{2}\right|}{g+1}\right)^{2}\right)\right)^{1 / 2} .
\end{gathered}
$$

With the generalization of (9) and (10), the generalized hesitant intuitionistic fuzzy linguistic distance can be obtained:

$$
\begin{gathered}
d_{\text {ghifld }}\left(E_{S}^{1}, E_{S}^{2}\right)=\left(\frac { 1 } { 2 } \left(\frac{1}{L} \sum_{l=1}^{L}\left(\frac{\left|\sigma_{l}^{1}-\sigma_{l}^{2}\right|}{g+1}\right)^{\lambda}\right.\right. \\
\left.\left.+\frac{1}{K} \sum_{k=1}^{K}\left(\frac{\left|\delta_{k}^{1}-\delta_{k}^{2}\right|}{g+1}\right)^{\lambda}\right)\right)^{1 / \lambda} .
\end{gathered}
$$

Based on the Hausdorff distance measure, the generalized hesitant intuitionistic fuzzy linguistic Hausdorff distance is expressed as

$$
\begin{gathered}
d_{\text {ghiglhd }}\left(E_{S}^{1}, E_{S}^{2}\right)=\left(\operatorname { m a x } \left\{\max _{l}\left(\frac{\left|\sigma_{l}^{1}-\sigma_{l}^{2}\right|}{g+1}\right)^{\lambda},\right.\right. \\
\left.\left.\max _{k}\left(\frac{\left|\delta_{k}^{1}-\delta_{k}^{2}\right|}{g+1}\right)^{\lambda}\right\}\right)^{1 / \lambda} .
\end{gathered}
$$

With the combination of (11) and (12), we get the generalized hybrid hesitant intuitionistic fuzzy linguistic distance:

$$
\begin{aligned}
& d_{\text {ghhigld }}\left(E_{S}^{1}, E_{S}^{2}\right)=\left(\frac { 1 } { 2 } \left(\frac { 1 } { 2 } \left(\frac{1}{L} \sum_{l=1}^{L}\left(\frac{\left|\sigma_{l}^{1}-\sigma_{l}^{2}\right|}{g+1}\right)^{\lambda}\right.\right.\right. \\
& \left.+\frac{1}{K} \sum_{k=1}^{K}\left(\frac{\left|\delta_{k}^{1}-\delta_{k}^{2}\right|}{g+1}\right)^{\lambda}\right) \\
& \left.\left.\quad+\max \left\{\max _{l}\left(\frac{\left|\sigma_{l}^{1}-\sigma_{l}^{2}\right|}{g+1}\right)^{\lambda}, \max _{k}\left(\frac{\left|\delta_{k}^{1}-\delta_{k}^{2}\right|}{g+1}\right)^{\lambda}\right\}\right)\right)^{1 / \lambda},
\end{aligned}
$$

where $\sigma_{l}^{1}$ and $\sigma_{l}^{2}$ are the $l$ th largest linguistic term in $H_{S}^{1}$ and $H_{S}^{2}$ and $\delta_{k}^{1}$ and $\delta_{k}^{2}$ are the $k$ th largest linguistic term in $G_{S}^{1}$ and $G_{S}^{2}$. 
Definition 9. The distance measure $d\left(E_{S}^{1}, E_{S}^{2}\right)$ between $E_{S}^{1}$ and $E_{S}^{2}$ satisfies the following properties:

(1) $0 \leq d\left(E_{S}^{1}, E_{S}^{2}\right) \leq 1$;

(2) $d\left(E_{S}^{1}, E_{S}^{2}\right)=0$ if and only if $E_{S}^{1}=E_{S}^{2}$;

(3) $d\left(E_{S}^{1}, E_{S}^{2}\right)=d\left(E_{S}^{2}, E_{S}^{1}\right)$.

\section{Proposed Method for MCDM}

The MCDM problem with hesitant intuitionistic fuzzy linguistic information is shown as follows. Suppose that there are $m$ alternatives $A=\left\{A_{1}, A_{2}, \ldots, A_{m}\right\}$ and $n$ criteria $C=$ $\left\{C_{1}, C_{2}, \ldots, C_{n}\right\}$; the weight vector of the criteria is $W=$ $\left(w_{1}, w_{2}, \ldots, w_{n}\right)$, where $w_{j} \geq 0, \sum_{j=1}^{n} w_{j}=1$; assume that the evaluation values are taken in the form of HIFLTSs, where $E_{i j}$ is the evaluation value of alternative $A_{i}$ respect to criteria $C_{j}$. Hence, we construct the hesitant intuitionistic fuzzy linguistic decision matrix $E=\left[E_{i j}\right]_{m \times n}$.

Note. This paper omits the process of transforming the linguistic information into HIFLTSs. The detailed process was shown in [11].

4.1. Normalized Decision Matrix. We should translate the decision matrix $E=\left[E_{i j}\right]_{m \times n}$ into the normalized decision matrix $\widetilde{E}=\left[\widetilde{E}_{i j}\right]_{m \times n}$ before calculating the grey relational bidirectional projection. In the MCDM system, there are usually two types of criteria, the benefit criteria and the cost criteria; the normalized $\widetilde{E}_{i j}$ is shown as

$$
\widetilde{E}_{i j}= \begin{cases}E_{i j}, & C_{j} \in \text { benefit criteria } \\ E_{i j}^{c}, & C_{j} \in \text { cost criteria. }\end{cases}
$$

4.2. Grey Relational Bidirectional Projection. Grey relational projection method combines the advantages of the grey relational analysis [35-40] and the projection method [41-44], which is an effective method to deal with MCDM problems. However, the traditional projection method sometimes has some shortcomings, for example, during the projection of two vectors $a$ and $c$ onto the ideal solution $b$ at the same vertical point, as shown in Figure 1. Their projection value is equal; that is, the alternatives can not be compared.

Ye [45] proposed the bidirectional projection method, which can overcome the shortcomings of the traditional projection method; that is,

$$
\begin{aligned}
\operatorname{BP}(a, b) & =\frac{1}{1+|(a \cdot b) /| a|-(a \cdot b) /| b||} \\
& =\frac{|a| \cdot|b|}{|a| \cdot|b|+|| a|-| b|| \cdot a \cdot b} .
\end{aligned}
$$

Motivated by Ye's method, we combine the grey relational analysis and the bidirectional projection method and propose the grey relational bidirectional projection method, which can rank the preference order of alternatives efficiently. Then, we present the grey relational bidirectional projection

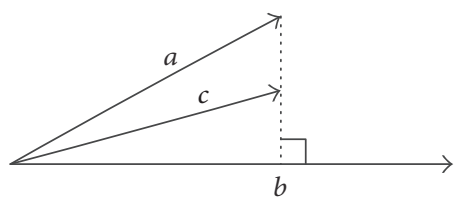

FIgURE 1: The projection vector.

method and apply it to the hesitant intuitionistic fuzzy linguistic MCDM.

Firstly, determine the hesitant intuitionistic fuzzy linguistic ideal solution. For a normalized hesitant intuitionistic fuzzy linguistic decision making matrix, the hesitant intuitionistic fuzzy linguistic positive ideal solution (HIFLPIS) and the hesitant intuitionistic fuzzy linguistic negative ideal solution (HIFLNIS) are expressed as

$$
\begin{aligned}
& \widetilde{E}^{+}=\left\{\widetilde{E}_{1}^{+}, \widetilde{E}_{2}^{+}, \ldots, \widetilde{E}_{n}^{+}\right\} \\
& \widetilde{E}^{-}=\left\{\widetilde{E}_{1}^{-}, \widetilde{E}_{2}^{-}, \ldots, \widetilde{E}_{n}^{-}\right\} .
\end{aligned}
$$

Then calculate the generalized hybrid hesitant intuitionistic fuzzy linguistic distance between $\widetilde{E}_{i j}$ and $\widetilde{E}^{+}$, and that between $\widetilde{E}_{i j}$ and $\widetilde{E}^{-}$is shown as

$$
\begin{aligned}
d_{i j}^{+} & =\left(\frac { 1 } { 2 } \left(\frac{1}{2}\left(\frac{1}{L} \sum_{l=1}^{L}\left(\frac{\left|\sigma_{l}^{i j}-\sigma_{l}^{+}\right|}{g+1}\right)^{\lambda}+\frac{1}{K} \sum_{k=1}^{K}\left(\frac{\left|\delta_{k}^{i j}-\delta_{k}^{+}\right|}{g+1}\right)^{\lambda}\right)\right.\right. \\
& \left.\left.+\max \left\{\max _{l}\left(\frac{\left|\sigma_{l}^{i j}-\sigma_{l}^{+}\right|}{g+1}\right)^{\lambda}, \max _{k}\left(\frac{\left|\delta_{k}^{i j}-\delta_{k}^{+}\right|}{g+1}\right)^{\lambda}\right\}\right)\right)^{1 / \lambda}, \\
d_{i j}^{-} & =\left(\frac { 1 } { 2 } \left(\frac{1}{2}\left(\frac{1}{L} \sum_{l=1}^{L}\left(\frac{\left|\sigma_{l}^{i j}-\sigma_{l}^{-}\right|}{g+1}\right)^{\lambda}+\frac{1}{K} \sum_{k=1}^{K}\left(\frac{\left|\delta_{k}^{i j}-\delta_{k}^{-}\right|}{g+1}\right)^{\lambda}\right)\right.\right. \\
& \left.\left.+\max \left\{\max _{l}\left(\frac{\left|\sigma_{l}^{i j}-\sigma_{l}^{-}\right|}{g+1}\right)^{\lambda}, \max _{k}\left(\frac{\left|\delta_{k}^{i j}-\delta_{k}^{-}\right|}{g+1}\right)^{\lambda}\right\}\right)\right)^{1 / \lambda} .
\end{aligned}
$$

Thus, the grey relational coefficient of each alternative from the HIFLPIS and HIFLNIS can be formulated as

$$
\begin{aligned}
r_{i j}^{+} & =\frac{\min _{i} \min _{j} d_{i j}^{+}+\theta \max _{i} \max _{j} d_{i j}^{+}}{d_{i j}^{+}+\theta \max _{i} \max _{j} d_{i j}^{+}}, \\
r_{i j}^{-} & =\frac{\min _{i} \min _{j} d_{i j}^{-}+\theta \max _{i} \max _{j} d_{i j}^{-}}{d_{i j}^{-}+\theta \max _{i} \max _{j} d_{i j}^{-}},
\end{aligned}
$$

where $\theta \in[0,1]$ is the resolution coefficient which is decided by the decision maker; thus we can construct the grey relational coefficient matrices $r^{+}=\left[r_{i j}^{+}\right]_{m \times n}$ and $r^{-}=\left[r_{i j}^{-}\right]_{m \times n}$. 
The grey relational coefficient between HIFLPIS and HIFLPIS and that between HIFLNIS and HIFLNIS are, respectively, shown as

$$
\begin{aligned}
& r_{0}^{+}=\left(r_{01}^{+}, r_{02}^{+}, \ldots, r_{0 n}^{+}\right)=\underbrace{1,1, \ldots, 1}_{n}, \\
& r_{0}^{-}=\left(r_{01}^{-}, r_{02}^{-}, \ldots, r_{0 n}^{-}\right)=\underbrace{1,1, \ldots, 1}_{n} .
\end{aligned}
$$

We can get the weighted grey relational coefficient matrices $R^{+}=\left[R_{i j}^{+}\right]_{m \times n}=\left[w_{j} r_{i j}^{+}\right]_{m \times n}$ and $R^{-}=\left[R_{i j}^{-}\right]_{m \times n}=$ $\left[w_{j} r_{i j}^{-}\right]_{m \times n}$.
The weighted grey relational coefficient between HIFLPIS and HIFLPIS and that between HIFLNIS and HIFLNIS are, respectively, shown as

$$
\begin{aligned}
& R_{0}^{+}=\left(R_{01}^{+}, R_{02}^{+}, \ldots, R_{0 n}^{+}\right)=\left(w_{1}, w_{2}, \ldots, w_{n}\right) \\
& R_{0}^{-}=\left(R_{01}^{-}, R_{02}^{-}, \ldots, R_{0 n}^{-}\right)=\left(w_{1}, w_{2}, \ldots, w_{n}\right)
\end{aligned}
$$

Combining the weighted grey relational coefficient and the bidirectional projection method, we get the weighted grey relational bidirectional projection between $R_{i}^{+}$and $R_{0}^{+}$, and that between $R_{i}^{-}$and $R_{0}^{-}$is, respectively, shown as

$$
\begin{aligned}
\mathrm{BP}_{i}^{+} & =\frac{1}{1+\left|\left(R_{i}^{+} \cdot R_{0}^{+}\right) /\right| R_{i}^{+}\left|-\left(R_{i}^{+} \cdot R_{0}^{+}\right) /\right| R_{0}^{+}||}=\frac{\left|R_{i}^{+}\right| \cdot\left|R_{0}^{+}\right|}{\left|R_{i}^{+}\right| \cdot\left|R_{0}^{+}\right|+|| R_{i}^{+}|-| R_{0}^{+}|| \cdot R_{i}^{+} \cdot R_{0}^{+}} \\
& =\frac{\sqrt{\sum_{j=1}^{n}\left(R_{i j}^{+}\right)^{2}} \cdot \sqrt{\sum_{j=1}^{n} w_{j}^{2}}}{\sqrt{\sum_{j=1}^{n}\left(R_{i j}^{+}\right)^{2}} \cdot \sqrt{\sum_{j=1}^{n} w_{j}^{2}}+\left|\sqrt{\sum_{j=1}^{n}\left(R_{i j}^{+}\right)^{2}}-\sqrt{\sum_{j=1}^{n} w_{j}^{2}}\right| \cdot \sum_{j=1}^{n} R_{i j}^{+} w_{j}}, \\
\mathrm{BP}_{i}^{-} & =\frac{1}{1+\left|\left(R_{i}^{-} \cdot R_{0}^{-}\right) /\right| R_{i}^{-}\left|-\left(R_{i}^{-} \cdot R_{0}^{-}\right) /\right| R_{0}^{-}||}=\frac{\left|R_{i}^{-}\right| \cdot\left|R_{0}^{-}\right|}{\left|R_{i}^{-}\right| \cdot\left|R_{0}^{-}\right|+|| R_{i}^{-}|-| R_{0}^{-}|| \cdot R_{i}^{-} \cdot R_{0}^{-}} \\
& =\frac{\sqrt{\sum_{j=1}^{n}\left(R_{i j}^{-}\right)^{2}} \cdot \sqrt{\sum_{j=1}^{n} w_{j}^{2}}}{\sqrt{\sum_{j=1}^{n}\left(R_{i j}^{-}\right)^{2}} \cdot \sqrt{\sum_{j=1}^{n} w_{j}^{2}}+\left|\sqrt{\sum_{j=1}^{n}\left(R_{i j}^{-}\right)^{2}}-\sqrt{\sum_{j=1}^{n} w_{j}^{2}}\right| \cdot \sum_{j=1}^{n} R_{i j}^{-} w_{j}} .
\end{aligned}
$$

For the alternative $A_{i}$, the closer the value of $\mathrm{BP}_{i}^{+}$is to 1 , the closer it is to HIFLPIS, the closer the value of $\mathrm{BP}_{i}^{-}$is to 1 , the closer it is to HIFLNIS, obviously, the larger the value of $\mathrm{BP}_{i}^{+}$is, the better $A_{i}$ is, and the smaller the value of $\mathrm{BP}_{i}^{-}$is, the better $A_{i}$ is and vice versa. Thus we construct the relative closeness formula.

$$
\widetilde{C}_{i}=\frac{\mathrm{BP}_{i}^{+}}{\mathrm{BP}_{i}^{+}+\mathrm{BP}_{i}^{-}} .
$$

In general, the larger $\widetilde{C}_{i}$ is, the better $A_{i}$ is and vice versa.

4.3. Determine the Attribute Weight. In this paper we consider the case where the criteria weight information is partly known. As we know, there are many methods for deriving criteria weights, such as the deviation-based method [46, 47] and the entropy-based method [48, 49]. We combine the advantages of the deviation-based method and the entropybased method and construct the combined optimization model.

We first construct the optimization model $M 1$ according to the minimum deviation method. The grey relational coefficient deviation between the alternative $A_{i}$ and HIFLPIS is $\left(1-r_{i j}^{+}\right)$, to eliminate the effects of symbols, we take the form of the squared, and totally, we have

$$
\begin{array}{cl}
M 1: \min & C_{1}(w)=\sum_{i=1}^{m} \sum_{j=1}^{n}\left[\left(1-r_{i j}^{+}\right) w_{j}\right]^{2} \\
\text { s.t. } & 0 \leq w_{j}^{L} \leq w_{j} \leq w_{j}^{U} \leq 1 \\
& \sum_{j=1}^{n} w_{j}=1 .
\end{array}
$$

The principle of information entropy method is that, in all feasible solutions or possible solutions, the maximum entropy is chosen. The maximum entropy means that the amount of information obtained is the smallest. In the process of solving, the amount of information added is the least, so the entropy-based method is reasonable when the criteria weight information is partly known. We construct the optimization model M2 as follows:

$$
\begin{array}{cl}
\text { M2: } \max & C_{2}(w)=-\sum_{j=1}^{n} w_{j} \ln w_{j} \\
\text { s.t. } & 0 \leq w_{j}^{L} \leq w_{j} \leq w_{j}^{U} \leq 1 \\
& \sum_{j=1}^{n} w_{j}=1 .
\end{array}
$$



M3:

Combine $M 1$ and $M 2$, then we have optimization model

$$
\begin{aligned}
& \text { M3: } \min \quad C(w) \\
& =\alpha \sum_{i=1}^{m} \sum_{j=1}^{n}\left[\left(1-r_{i j}^{+}\right) w_{j}\right]^{2} \\
& \\
& \quad-(1-\alpha) \sum_{j=1}^{n} w_{j} \ln w_{j} \\
& \text { s.t. } \quad 0 \leq w_{j}^{L} \leq w_{j} \leq w_{j}^{U} \leq 1 \\
& \\
& \sum_{j=1}^{n} w_{j}=1,
\end{aligned}
$$

where $\alpha$ represents the equilibrium coefficient; without losing generality, we let $\alpha=0.5$. The criteria weights can be obtained by Matlab software.

4.4. The Procedure of the MCDM Method. The algorithm for the proposed method is shown as follows.

Step 1. Construct the decision matrix $E=\left[E_{i j}\right]_{m \times n}$, then translate the decision matrix into the normalized decision matrix $\widetilde{E}=\left[\widetilde{E}_{i j}\right]_{m \times n}$.

Step 2. Determine the hesitant intuitionistic fuzzy linguistic positive ideal solution (HIFLPIS) $\widetilde{E}^{+}$and the hesitant intuitionistic fuzzy linguistic negative ideal solution (HIFLNIS) $\widetilde{E}^{-}$, according to Definition 7 .
Step 3. Calculate the generalized hybrid hesitant intuitionistic fuzzy linguistic distance between $\widetilde{E}_{i j}$ and $\widetilde{E}^{+}$and that between $\widetilde{E}_{i j}$ and $\widetilde{E}^{-}$, shown in (17), based on the distance measure. We get the grey relational coefficient of each alternative from the HIFLPIS and HIFLNIS, according to (18), then the grey relational coefficient matrices $r^{+}=\left[r_{i j}^{+}\right]_{m \times n}$ and $r^{-}=\left[r_{i j}^{-}\right]_{m \times n}$ are constructed.

Step 4. Obtain the criteria weight by solving the optimization model $M 3$.

Step 5. Calculate the grey relational bidirectional projection between each alternative and the HIFLPIS and that between each alternative and the HIFLNIS, according to (21); thus, the relative closeness can be constructed in (22).

Step 6. Rank all alternatives according to the relative closeness.

\section{Illustrative Example}

5.1. Example. In this section, an illustrative example about courses evaluation for a MCDM problem adopted from [28] is given to show the method proposed in this paper. There are three courses we need to evaluate, $A_{1}, A_{2}$, and $A_{3}$, and four criteria, $C_{1}, C_{2}, C_{3}$, and $C_{4}$. The criteria weights information is partly known, assuming $0.38 \leq w_{1} \leq 0.42,0.30 \leq w_{2} \leq 0.35$, $0.18 \leq w_{3} \leq 0.21$, and $0.07 \leq w_{4} \leq 0.09$. The linguistic term set $S=\left\{s_{0}, s_{1}, s_{2}, s_{3}, s_{4}, s_{5}, s_{6}\right\}=\left\{s_{0}=\right.$ very poor, $s_{1}=$ poor, $s_{2}=$ medium, $s_{3}=$ fair, $s_{4}=$ medium good, $s_{5}=$ good, $s_{6}=$ very good $\}$, the linguistic information. The evaluation information takes the form of HIFLTSs, where $E_{i j}$ is the evaluation value of the alternative $A_{i}$ on the criteria $C_{j}$, and then the decision matrix is as follows:

$$
E=\left[\begin{array}{cccc}
\left\{\left(s_{2}, s_{3}\right),\left(s_{0}\right)\right\}, & \left\{\left(s_{4}, s_{5}, s_{6}\right),\left(s_{0}\right)\right\}, & \left\{\left(s_{0}, s_{1}, s_{2}\right),\left(s_{4}\right)\right\}, & \left\{\left(s_{4}, s_{5}\right),\left(s_{0}, s_{1}\right)\right\} \\
\left\{\left(s_{3}\right),\left(s_{2}, s_{3}\right)\right\}, & \left\{\left(s_{2}, s_{3}, s_{4}\right),\left(s_{0}, s_{1}\right)\right\}, & \left\{\left(s_{2}, s_{3}\right),\left(s_{3}, s_{4}\right)\right\}, & \left\{\left(s_{6}\right),\left(s_{0}\right)\right\} \\
\left\{\left(s_{3}, s_{4}\right),\left(s_{0}, s_{1}\right)\right\}, & \left\{\left(s_{3}, s_{4}\right),\left(s_{0}, s_{2}\right)\right\}, & \left\{\left(s_{4}\right),\left(s_{0}, s_{2}\right)\right\}, & \left\{\left(s_{0}, s_{1}, s_{2}, s_{3}\right),\left(s_{3}\right)\right\}
\end{array}\right] .
$$

The procedure to obtain the most desirable alternative is as follows.
Step 1. Transform the decision matrix $E=\left[E_{i j}\right]_{3 \times 4}$ into the normalized decision matrix $\widetilde{E}=\left[\widetilde{E}_{i j}\right]_{3 \times 4}$. We get

$$
\widetilde{E}=\left[\begin{array}{llll}
\left\{\left(s_{2}, s_{3}\right),\left(s_{0}, s_{0}\right)\right\}, & \left\{\left(s_{4}, s_{5}, s_{6}\right),\left(s_{0}, s_{0}\right)\right\}, & \left\{\left(s_{0}, s_{1}, s_{2}\right),\left(s_{4}, s_{4}\right)\right\}, & \left\{\left(s_{4}, s_{4}, s_{4}, s_{5}\right),\left(s_{0}, s_{1}\right)\right\} \\
\left\{\left(s_{3}, s_{3}\right),\left(s_{2}, s_{3}\right)\right\}, & \left\{\left(s_{2}, s_{3}, s_{4}\right),\left(s_{0}, s_{1}\right)\right\}, & \left\{\left(s_{2}, s_{2}, s_{3}\right),\left(s_{3}, s_{4}\right)\right\}, & \left\{\left(s_{6}, s_{6}, s_{6}, s_{6}\right),\left(s_{0}, s_{0}\right)\right\} \\
\left\{\left(s_{3}, s_{4}\right),\left(s_{0}, s_{1}\right)\right\}, & \left\{\left(s_{3}, s_{3}, s_{4}\right),\left(s_{0}, s_{2}\right)\right\}, & \left\{\left(s_{4}, s_{4}, s_{4}\right),\left(s_{0}, s_{2}\right)\right\}, & \left\{\left(s_{0}, s_{1}, s_{2}, s_{3}\right),\left(s_{3}, s_{3}\right)\right\}
\end{array}\right] .
$$

Step 2. According to Definition 7, we determine HIFLPIS and HIFLNIS and have

$$
\begin{aligned}
& \widetilde{E}^{+}=\left\{\left\{\left(s_{3}, s_{4}\right),\left(s_{0}, s_{1}\right)\right\},\left\{\left(s_{4}, s_{5}, s_{6}\right),\left(s_{0}, s_{0}\right)\right\},\left\{\left(s_{4}, s_{4}, s_{4}\right),\left(s_{0}, s_{2}\right)\right\},\left\{\left(s_{6}, s_{6}, s_{6}, s_{6}\right),\left(s_{0}, s_{0}\right)\right\}\right\}, \\
& \widetilde{E}^{-}=\left\{\left\{\left(s_{3}, s_{3}\right),\left(s_{2}, s_{3}\right)\right\},\left\{\left(s_{2}, s_{3}, s_{4}\right),\left(s_{0}, s_{1}\right)\right\},\left\{\left(s_{0}, s_{1}, s_{2}\right),\left(s_{4}, s_{4}\right)\right\},\left\{\left(s_{0}, s_{1}, s_{2}, s_{3}\right),\left(s_{3}, s_{3}\right)\right\}\right\} .
\end{aligned}
$$


Step 3. Calculate the generalized hybrid hesitant intuitionistic fuzzy linguistic distances $d_{i j}^{+}$and $d_{i j}^{-}$, based on (17), let $\lambda=2$, and then we construct the distance matrix as follows:

$$
\begin{aligned}
& D^{+}=\left[\begin{array}{llll}
0.1336 & 0.0000 & 0.5273 & 0.2720 \\
0.2525 & 0.2673 & 0.3712 & 0.0000 \\
0.0000 & 0.2525 & 0.0000 & 0.7660
\end{array}\right], \\
& D^{-}=\left[\begin{array}{llll}
0.3571 & 0.2673 & 0.0000 & 0.4974 \\
0.0000 & 0.0000 & 0.2422 & 0.7660 \\
0.2525 & 0.1129 & 0.5273 & 0.0000
\end{array}\right] .
\end{aligned}
$$

According to (18), we calculate the grey relational coefficient of each alternative from HIFLPIS and HIFLNIS, without losing generality; let $\theta=0.5$. We have

$$
\begin{aligned}
& r^{+}=\left[\begin{array}{llll}
0.7413 & 1.0000 & 0.4207 & 0.5847 \\
0.6026 & 0.5890 & 0.5079 & 1.0000 \\
1.0000 & 0.6026 & 1.0000 & 0.3333
\end{array}\right], \\
& r^{-}=\left[\begin{array}{llll}
0.5175 & 0.5890 & 1.0000 & 0.4350 \\
1.0000 & 1.0000 & 0.6126 & 0.3333 \\
0.6026 & 0.7723 & 0.4207 & 1.0000
\end{array}\right] .
\end{aligned}
$$

Step 4. Solve the optimization model $M 3$ by using the fmincon function in Matlab software. We get

$$
W=(0.3837,0.3163,0.2100,0.0900)^{T} .
$$

Step 5. Calculate the grey relational bidirectional projection between each alternative and the HIFLPIS and the grey relational bidirectional projection between each alternative and the HIFLNIS, according to (21). We have

$$
\begin{aligned}
& \mathrm{BP}_{1}^{+}=0.9040, \\
& \mathrm{BP}_{2}^{+}=0.8216, \\
& \mathrm{BP}_{3}^{+}=0.9374, \\
& \mathrm{BP}_{1}^{-}=0.8376, \\
& \mathrm{BP}_{2}^{-}=0.9691, \\
& \mathrm{BP}_{3}^{-}=0.8445 .
\end{aligned}
$$

Calculate the relative closeness, shown in (22). We obtain

$$
\begin{aligned}
& \widetilde{C}_{1}=0.5191, \\
& \widetilde{C}_{2}=0.4588, \\
& \widetilde{C}_{3}=0.5261 .
\end{aligned}
$$

TABLE 1: The relative closeness with respect to $\lambda=2$.

\begin{tabular}{ccccc}
\hline$\theta$ & $A_{1}$ & $A_{2}$ & $A_{3}$ & Rankings \\
\hline 0.2 & 0.4922 & 0.4506 & 0.5550 & $A_{3}>A_{1}>A_{2}$ \\
0.4 & 0.4980 & 0.4611 & 0.5445 & $A_{3}>A_{1}>A_{2}$ \\
0.6 & 0.4999 & 0.4684 & 0.5370 & $A_{3}>A_{1}>A_{2}$ \\
0.8 & 0.5005 & 0.4734 & 0.5317 & $A_{3}>A_{1}>A_{2}$ \\
1.0 & 0.5007 & 0.4771 & 0.5277 & $A_{3}>A_{1}>A_{2}$ \\
\hline
\end{tabular}

TABLE 2: The relative closeness with respect to $\lambda=5$.

\begin{tabular}{ccccc}
\hline$\theta$ & $A_{1}$ & $A_{2}$ & $A_{3}$ & Rankings \\
\hline 0.2 & 0.4923 & 0.4504 & 0.5558 & $A_{3}>A_{1}>A_{2}$ \\
0.4 & 0.4984 & 0.4608 & 0.5452 & $A_{3}>A_{1}>A_{2}$ \\
0.6 & 0.5005 & 0.4681 & 0.5376 & $A_{3}>A_{1}>A_{2}$ \\
0.8 & 0.5012 & 0.4731 & 0.5322 & $A_{3}>A_{1}>A_{2}$ \\
1.0 & 0.5014 & 0.4768 & 0.5282 & $A_{3}>A_{1}>A_{2}$ \\
\hline
\end{tabular}

Step 6. Rank all the alternatives

$$
A_{3}>A_{1}>A_{2} \text {. }
$$

Furthermore, for comparative analysis, we apply the weight vector of the criteria in [26], then the result is as follows.

Step $5^{*}$. Calculate the grey relational bidirectional projection between each alternative and the HIFLPIS and the grey relational bidirectional projection between each alternative and the HIFLNIS, according to (21). We have

$$
\begin{aligned}
& \mathrm{BP}_{1}^{+}=0.8671, \\
& \mathrm{BP}_{2}^{+}=0.8270, \\
& \mathrm{BP}_{3}^{+}=0.9702, \\
& \mathrm{BP}_{1}^{-}=0.8690 \\
& \mathrm{BP}_{2}^{-}=0.9433, \\
& \mathrm{BP}_{3}^{-}=0.8319
\end{aligned}
$$

Calculate the relative closeness, shown in (22). We obtain

$$
\begin{aligned}
& \widetilde{C}_{1}=0.4995, \\
& \widetilde{C}_{2}=0.4671, \\
& \widetilde{C}_{3}=0.5384 .
\end{aligned}
$$

Step $6^{*}$. Rank all the alternatives

$$
A_{3}>A_{1}>A_{2} \text {. }
$$

The results are the same as those in [26], so the proposed method in this paper is effective.

From Tables $1-4$, we note that when the parameters $\theta, \lambda$ change, the relative closeness changes trends: when $\lambda$ is fixed, 
TABLE 3: The relative closeness with respect to $\theta=0.2$.

\begin{tabular}{lcccc}
\hline$\lambda$ & $A_{1}$ & $A_{2}$ & $A_{3}$ & Rankings \\
\hline 2 & 0.4922 & 0.4506 & 0.5550 & $A_{3}>A_{1}>A_{2}$ \\
4 & 0.4922 & 0.4504 & 0.5557 & $A_{3}>A_{1}>A_{2}$ \\
6 & 0.4923 & 0.4504 & 0.5559 & $A_{3}>A_{1}>A_{2}$ \\
8 & 0.4924 & 0.4504 & 0.5559 & $A_{3}>A_{1}>A_{2}$ \\
10 & 0.4924 & 0.4504 & 0.5559 & $A_{3}>A_{1}>A_{2}$ \\
\hline
\end{tabular}

TABLE 4: The relative closeness with respect to $\theta=0.5$.

\begin{tabular}{lcccc}
\hline$\lambda$ & $A_{1}$ & $A_{2}$ & $A_{3}$ & Rankings \\
\hline 2 & 0.4992 & 0.4651 & 0.5404 & $A_{3}>A_{1}>A_{2}$ \\
4 & 0.4996 & 0.4648 & 0.5410 & $A_{3}>A_{1}>A_{2}$ \\
6 & 0.4998 & 0.4648 & 0.5411 & $A_{3}>A_{1}>A_{2}$ \\
8 & 0.5000 & 0.4648 & 0.5411 & $A_{3}>A_{1}>A_{2}$ \\
10 & 0.5000 & 0.4649 & 0.5411 & $A_{3}>A_{1}>A_{2}$ \\
\hline
\end{tabular}

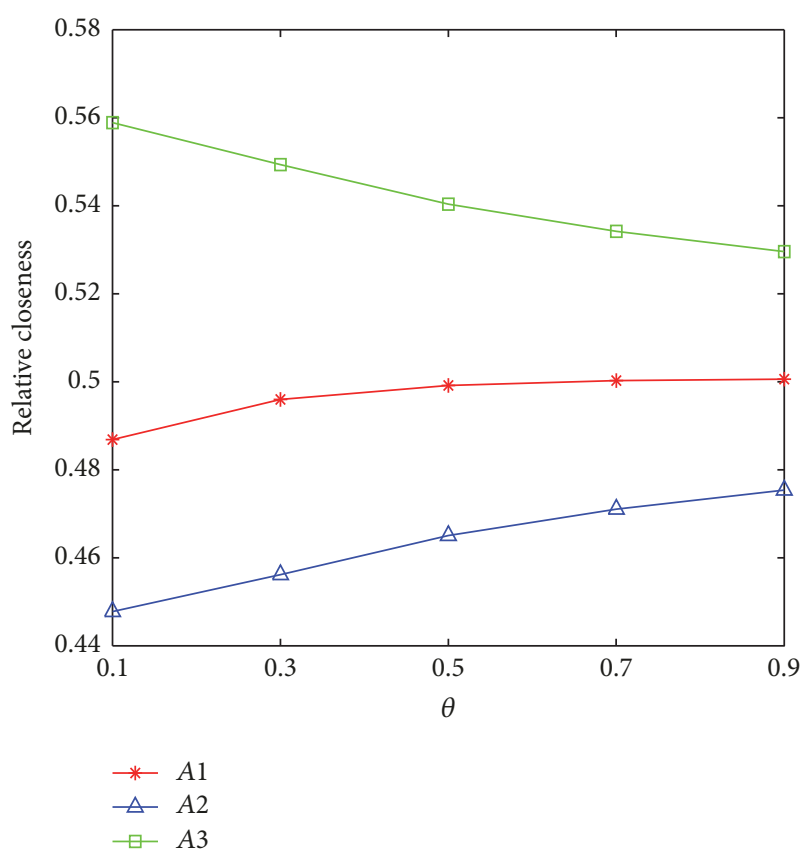

Figure 2: Relative closeness with respect to $\theta$ when $\lambda=2$.

the change $\theta$ has obvious effect on the relative closeness, but when $\theta$ is fixed, the change $\lambda$ has no obvious effect on the relative closeness. All ranking results are $A_{3}>A_{1}>A_{2}$, which means that $A_{3}$ is the best alternative. Moreover, the trends of the relative closeness of three alternatives can be shown directly in Figures 2-5, and we also present the relative closeness for the three alternatives when $\lambda$ and $\theta$ change simultaneously, which is shown in Figures 6-8; the results show that $A_{3}$ is always the best alternative. Thus, the choice of the parameter $\theta$ can reflect the decision maker's risk attitude, if the decision maker is risk averse, let $\theta$ be a larger value, and vice versa.

\subsection{Advantages of the Proposed Method}

(1) Compared with the possibility degree of HFLTSs studied in [11-13], the possibility degree formula proposed in this paper can overcome the drawback of the

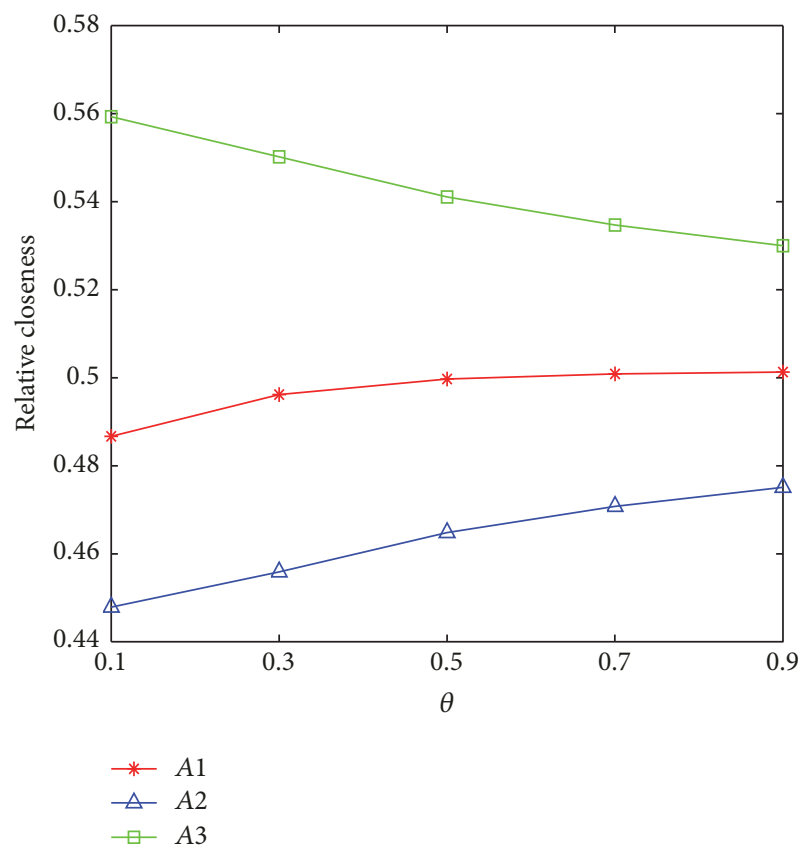

FIgURE 3: Relative closeness with respect to $\theta$ when $\lambda=5$.

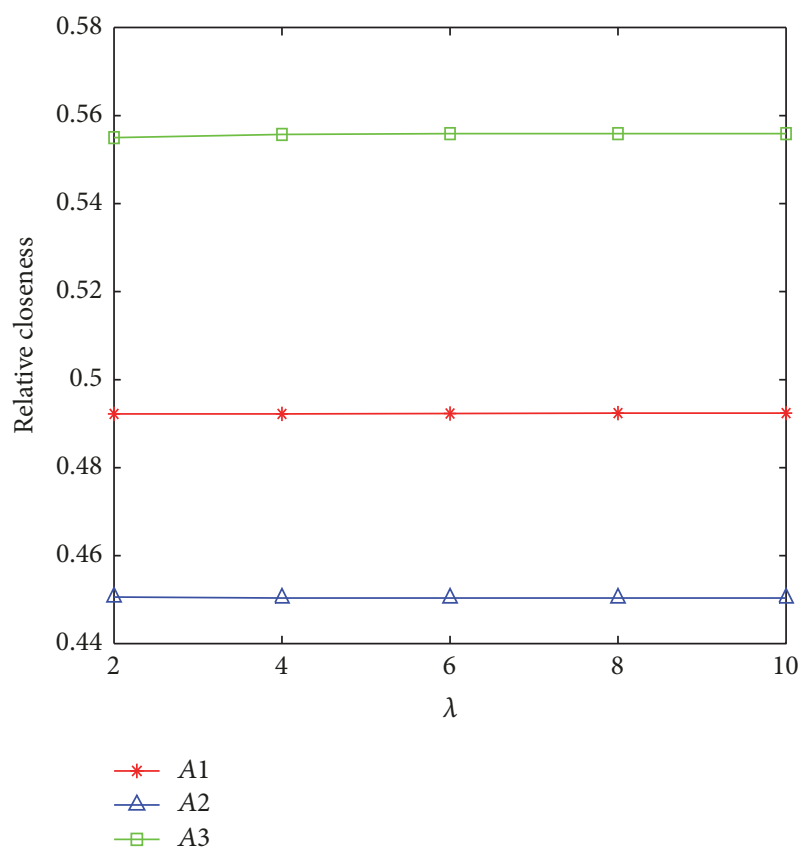

FIgURE 4: Relative closeness with respect to $\lambda$ when $\theta=0.2$.

previous work. We derived the possibility degree of HIFLTSs based on the possibility degree of HFLTSs, which can compare the HIFLTSs more effectively. Moreover, the possibility degree and the distance measure which are proposed in this paper are not only the foundation of the proposed grey relational bidirectional projection method but also foundation of many classical decision making methods including TOPSIS, PROMETHEE, and VIKOR. 


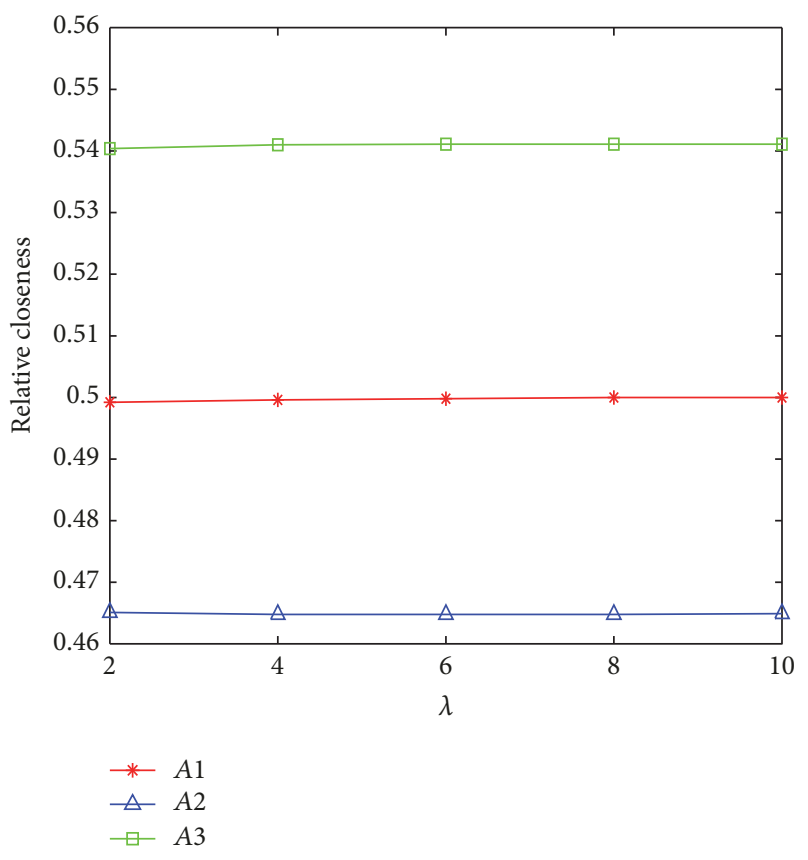

FIgURE 5: Relative closeness with respect to $\lambda$ when $\theta=0.5$.

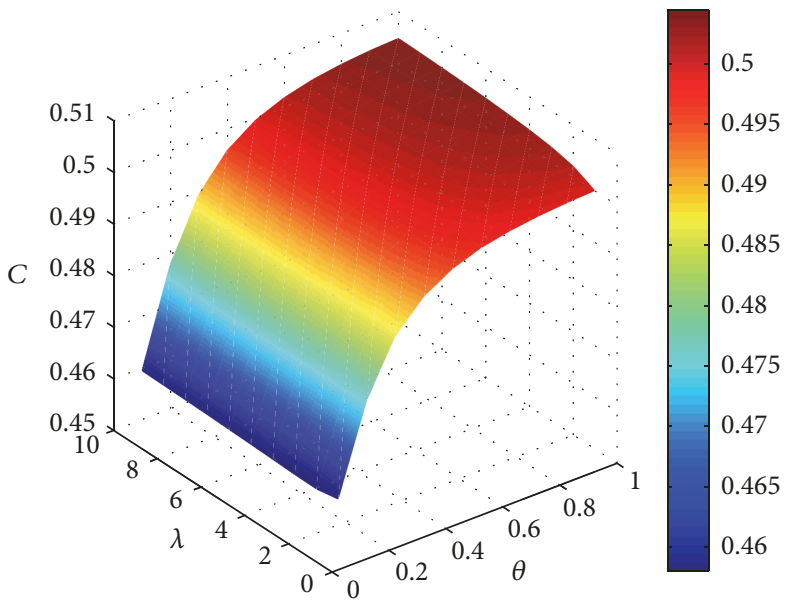

FIgURE 6: Relative closeness for $A_{1}(\lambda \in(0,10], \theta \in(0,1])$.

(2) In contrast to the studies in $[15,22]$, the grey relational bidirectional projection method combines the distance measure and the correlation coefficient, which can integrate the influence of the whole criteria space and avoid the unidirectional deviation.

(3) The criteria weights are determined by the nonlinear optimization model, which consists of the minimum deviation model $[46,47]$ and the information entropy model $[48,49]$. The optimization model combines the advantages of both methods, which is based on the evaluation and the weights information. Therefore, we can reduce the impact of subjective human factors and obtain the reasonable criteria weights.

(4) The proposed grey relational bidirectional projection method integrates the grey relational analysis into the

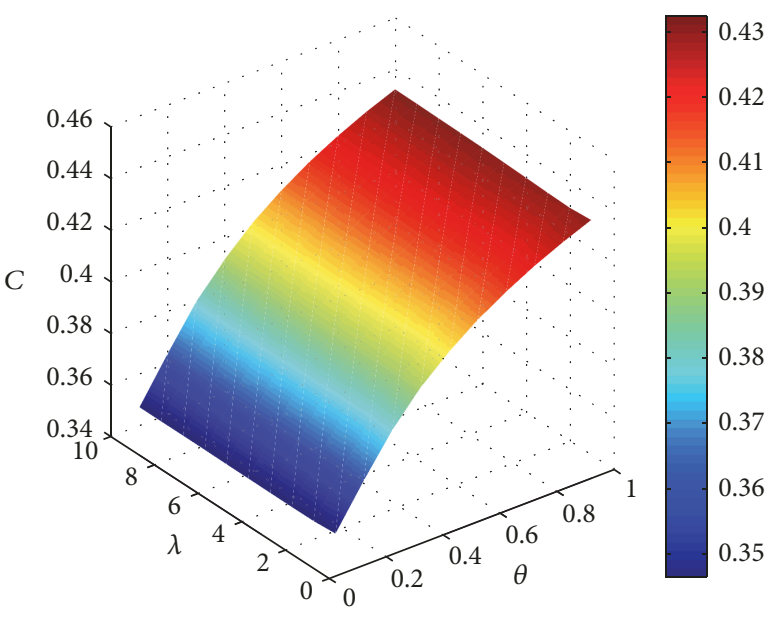

Figure 7: Relative closeness for $A_{2}(\lambda \in(0,10], \theta \in(0,1])$.

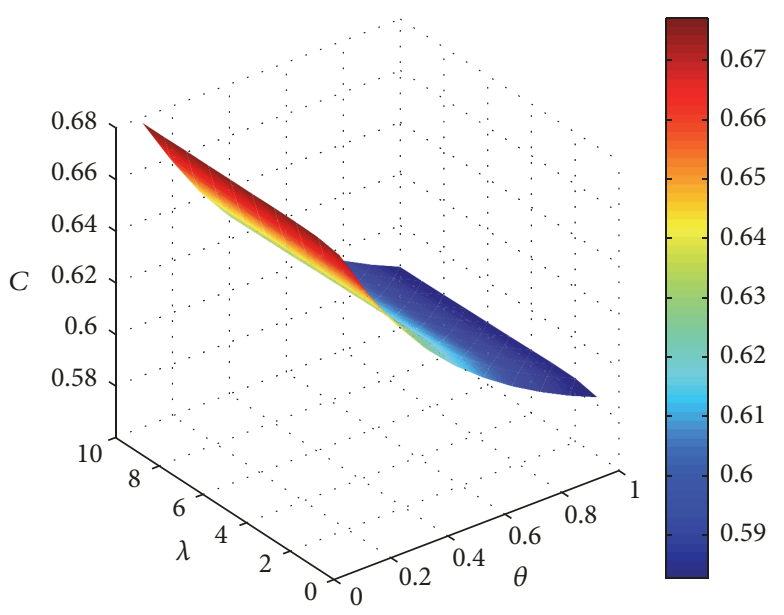

Figure 8: Relative closeness for $A_{3}(\lambda \in(0,10], \theta \in(0,1])$.

bidirectional projection. The method can overcome the drawbacks of the traditional grey relational projection [30-32], which cannot rank the preference order of the alternative in some situations.

\section{Conclusion}

The hesitant intuitionistic fuzzy linguistic term sets have a good advantage in the expression of hesitation information, which is especially important in the background of qualitative decision making. In this paper, we have investigated a novel qualitative decision making method based on the grey relational bidirectional projection with the hesitant intuitionistic fuzzy linguistic information. We have derived the possibility degree for comparing the HIFLTSs. We have proposed a family of distance measure for the HIFLTSs. Based on the possibility degree and the distance measure, we have proposed the grey relational bidirectional projection method, which combines the grey relational analysis and the vector projection theory. The combined nonlinear optimization model has been used to determine the criteria weight, 
where the information on criteria weights is partly known. The numerical example shows that the proposed method is suitable for dealing with the MCDM. Moreover, the model has good practicability and can be further applied in wider fields.

In future research, we will apply our possibility degree and distance measures to order decision making methods, such as ELECTRE and PROMETHEE. Furthermore, we will also focus on the extended hesitant intuitionistic fuzzy linguistic term sets theory, including the interval-valued hesitant intuitionistic fuzzy linguistic term sets and the hesitant intuitionistic fuzzy uncertain linguistic term sets.

\section{Conflicts of Interest}

The authors declare that there are no conflicts of interest regarding the publication of this paper.

\section{Acknowledgments}

The authors would like to acknowledge the support from the National Natural Science Foundation of China (nos. 71671159 and 71301139), the Natural Science Foundation of Hebei Province (nos. G2018203302 and G2016203236), the Project Funded by Hebei Education Department (nos. BJ2017029 and BJ2016063), and Hebei Talents Program (no. A2017002108).

\section{References}

[1] L. A. Zadeh, "The concept of a linguistic variable and its application to approximate reasoning-I," Information Sciences, vol. 8, no. 3, pp. 199-249, 1975.

[2] J. Ye, "Multiple attribute group decision making based on interval neutrosophic uncertain linguistic variables," International Journal of Machine Learning and Cybernetics, vol. 8, no. 3, pp. 1-12, 2015.

[3] R. Verma, "Multiple attribute group decision making based on generalized trapezoid fuzzy linguistic prioritized weighted average operator," International Journal of Machine Learning and Cybernetics, vol. 8, no. 6, pp. 1993-2007, 2017.

[4] H. Zhang, "Uncertain linguistic power geometric operators and their use in multiattribute group decision making," Mathematical Problems in Engineering, vol. 2015, Article ID 948380, 2015.

[5] K.-Y. Song, G. T. G. Seniuk, J. A. Kozinski, W.-J. Zhang, and M. M. Gupta, "An innovative fuzzy-neural decision analyzer for qualitative group decision making," International Journal of Information Technology \& Decision Making, vol. 14, no. 3, pp. 659-696, 2015.

[6] W. Yang, Y. Pang, J. Shi, and C. Wang, "Linguistic hesitant intuitionistic fuzzy decision-making method based on VIKOR," Neural Computing and Applications, pp. 1-14, 2016.

[7] Y. Ju and S. Yang, "A new method for multiple attribute group decision-making with intuitionistic trapezoid fuzzy linguistic information," Soft Computing, vol. 19, no. 8, pp. 2211-2224, 2015.

[8] C.-S. Lin, C.-T. Chen, F.-S. Chen, and W.-Z. Hung, "A novel multiperson game approach for linguistic multicriteria decision making problems," Mathematical Problems in Engineering, vol. 2014, Article ID 592326, 2014.

[9] D.-C. Luo, M.-H. Yang, and L.-F. Gao, "Research on risk assessment of financial market's venture capital project with hesitant fuzzy uncertain linguistic information," Journal of Computational and Theoretical Nanoscience, vol. 13, no. 10, pp. 7115-7119, 2016.

[10] S. Yang, Z. Sun, Y. Ju, and C. Qiao, "A Novel multiple attribute satisfaction evaluation approach with hesitant intuitionistic linguistic fuzzy information," Mathematical Problems in Engineering, vol. 2014, Article ID 692782, pp. 1-15, 2014.

[11] R. M. Rodriguez, L. Martinez, and F. Herrera, "Hesitant fuzzy linguistic term sets for decision making," IEEE Transactions on Fuzzy Systems, vol. 20, no. 1, pp. 109-119, 2012.

[12] C. Wei, N. Zhao, and X. Tang, "Operators and comparisons of hesitant fuzzy linguistic term sets," IEEE Transactions on Fuzzy Systems, vol. 22, no. 3, pp. 575-585, 2014.

[13] L.-W. Lee and S.-M. Chen, "Fuzzy decision making based on likelihood-based comparison relations of hesitant fuzzy linguistic term sets and hesitant fuzzy linguistic operators," Information Sciences, vol. 294, pp. 513-529, 2015.

[14] Z.-P. Tian, J. Wang, J.-Q. Wang, and H.-Y. Zhang, "A likelihoodbased qualitative flexible approach with hesitant fuzzy linguistic information," Cognitive Computation, vol. 8, no. 4, pp. 670-683, 2016.

[15] H. Liao, Z. Xu, and X.-J. Zeng, "Distance and similarity measures for hesitant fuzzy linguistic term sets and their application in multi-criteria decision making," Information Sciences, vol. 271, pp. 125-142, 2014.

[16] H. Liao and $\mathrm{Z}$. Xu, "Approaches to manage hesitant fuzzy linguistic information based on the cosine distance and similarity measures for HFLTSs and their application in qualitative decision making," Expert Systems with Applications, vol. 42, no. 12, pp. 5328-5336, 2015.

[17] J.-Q. Wang, J.-T. Wu, J. Wang, H.-Y. Zhang, and X.-H. Chen, "Multi-criteria decision-making methods based on the Hausdorff distance of hesitant fuzzy linguistic numbers," Soft Computing, vol. 20, no. 4, pp. 1621-1633, 2016.

[18] J.-Q. Wang, J. Wang, Q.-H. Chen, H.-Y. Zhang, and X.-H. Chen, "An outranking approach for multi-criteria decision-making with hesitant fuzzy linguistic term sets," Information Sciences, vol. 280, pp. 338-351, 2014.

[19] F. Meng and X. Chen, "A hesitant fuzzy linguistic multigranularity decision making model based on distance measures," Journal of Intelligent \& Fuzzy Systems: Applications in Engineering and Technology, vol. 28, no. 4, pp. 1519-1531, 2015.

[20] H. Liao, Z. Xu, and X.-J. Zeng, "Hesitant Fuzzy Linguistic VIKOR Method and Its Application in Qualitative Multiple Criteria Decision Making," IEEE Transactions on Fuzzy Systems, vol. 23, no. 5, pp. 1343-1355, 2015.

[21] C. Wei, Z. Ren, and R. M. Rodríguez, "A hesitant fuzzy linguistic TODIM method based on a score function," International Journal of Computational Intelligence Systems, vol. 8, no. 4, pp. 701-712, 2015.

[22] H. Liao, Z. Xu, X.-J. Zeng, and J. M. Merigó, "Qualitative decision making with correlation coefficients of hesitant fuzzy linguistic term sets," Knowledge-Based Systems, vol. 76, pp. 127138,2015

[23] R. Lin, X. Zhao, H. Wang, and G. Wei, "Hesitant fuzzy linguistic aggregation operators and their application to multiple attribute decision making," Journal of Intelligent \& Fuzzy Systems: Applications in Engineering and Technology, vol. 27, no. 1, pp. 49-63, 2014.

[24] B. Farhadinia, "Multiple criteria decision-making methods with completely unknown weights in hesitant fuzzy linguistic term setting," Knowledge-Based Systems, vol. 93, pp. 135-144, 2016. 
[25] X. Gou, Z. Xu, and H. Liao, "Hesitant fuzzy linguistic entropy and cross-entropy measures and alternative queuing method for multiple criteria decision making," Information Sciences, vol. 388-389, pp. 225-246, 2017.

[26] I. Beg and T. Rashid, "TOPSIS for hesitant fuzzy linguistic term sets," International Journal of Intelligent Systems, vol. 28, no. 12, pp. 1162-1171, 2013.

[27] X. Y. Liu, Y. B. Ju, and S. H. Yang, "Hesitant intuitionistic fuzzy linguistic aggregation operators and their applications to multiple attribute decision making," Journal of Intelligent \& Fuzzy Systems: Applications in Engineering and Technology, 2014.

[28] T. Rashid, S. Faizi, Z. Xu, and S. Zafar, "ELECTRE-based outranking method for multi-criteria decision making using hesitant intuitionistic fuzzy linguistic term sets," International Journal of Fuzzy Systems, 2017.

[29] S. Faizi, T. Rashid, and S. Zafar, "An outranking method for multi-criteria group decision making using hesitant intuitionistic fuzzy linguistic term sets," Journal of Intelligent \& Fuzzy Systems: Applications in Engineering and Technology, vol. 32, no. 3, pp. 2153-2164, 2017.

[30] G. Zheng, Y. Jing, H. Huang, and Y. Gao, "Application of improved grey relational projection method to evaluate sustainable building envelope performance," Applied Energy, vol. 87, no. 2, pp. 710-720, 2010.

[31] X. Zhang, F. Jin, and P. Liu, "A grey relational projection method for multi-attribute decision making based on intuitionistic trapezoidal fuzzy number," Applied Mathematical Modelling, vol. 37, no. 5, pp. 3467-3477, 2013.

[32] H.-C. Liu, J.-X. You, X.-J. Fan, and Q.-L. Lin, "Failure mode and effects analysis using D numbers and grey relational projection method," Expert Systems with Applications, vol. 41, no. 10, pp. 4670-4679, 2014.

[33] M. Delgado, J. L. Verdegay, and M. A. Vila, "Linguistic decisionmaking models," International Journal of Intelligent Systems, vol. 7, no. 5, pp. 479-492, 1992.

[34] Z. S. Xu, "Deviation measures of linguistic preference relations in group decision making," Omega, vol. 33, no. 3, pp. 249-254, 2005.

[35] Y. Kuo, T. Yang, and G.-W. Huang, “The use of grey relational analysis in solving multiple attribute decision-making problems," Computers and Industrial Engineering, vol. 55, no. 1, pp. 80-93, 2008.

[36] Y.-C. Hu, "A novel fuzzy classifier with Choquet integral-based grey relational analysis for pattern classification problems," Soft Computing, vol. 12, no. 6, pp. 523-533, 2008.

[37] G. Wei, "Gray relational analysis method for intuitionistic fuzzy multiple attribute decision making," Expert Systems with Applications, vol. 38, no. 9, pp. 11671-11677, 2011.

[38] S. Pramanik and D. Mukhopadhyaya, "Grey relational analysis based intuitionistic fuzzy multi-criteria group decision-making approach for teacher selection in higher education," International Journal of Computer Application, vol. 34, pp. 21-29, 2013.

[39] H. X. Tang, "A novel fuzzy soft set approach in decision making based on grey relational analysis and Dempster-Shafer theory of evidence," Applied Soft Computing, vol. 31, pp. 317-325, 2015.

[40] N. Xie, Y. Han, and Z. Li, "A novel approach to fuzzy soft sets in decision making based on grey relational analysis and MYCIN certainty factor," International Journal of Computational Intelligence Systems, vol. 8, no. 5, pp. 959-976, 2015.

[41] Z. Xu and Q. Da, "Projection method for uncertain multiattribute decision making with preference information on alternatives," International Journal of Information Technology and Decision Making, vol. 3, no. 3, pp. 429-434, 2004.

[42] S. Zeng, T. Balezentis, J. Chen, and G. Luo, "A projection method for multiple attribute group decision making with intuitionistic fuzzy information," Informatica, vol. 24, no. 3, pp. 485-503, 2013.

[43] Z. Yue, "Approach to group decision making based on determining the weights of experts by using projection method," Applied Mathematical Modelling, vol. 36, no. 7, pp. 2900-2910, 2012.

[44] Y. Ju and A. Wang, "Projection method for multiple criteria group decision making with incomplete weight information in linguistic setting," Applied Mathematical Modelling, vol. 37, no. 20-21, pp. 9031-9040, 2013.

[45] J. Ye, "Bidirectional projection method for multiple attribute group decision making with neutrosophic numbers," Neural Computing and Applications, vol. 28, no. 5, pp. 1-9, 2015.

[46] G. Wei and X. Zhao, "Minimum deviation models for multiple attribute decision making in intuitionistic fuzzy setting," International Journal of Computational Intelligence Systems, vol. 4, no. 2, pp. 174-183, 2011.

[47] R. Sahin and P. Liu, "Maximizing deviation method for neutrosophic multiple attribute decision making with incomplete weight information," Neural Computing Applications, vol. 7, pp. $1-13,2010$.

[48] D.-L. Mon, C.-H. Cheng, and J.-C. Lin, "Evaluating weapon system using fuzzy analytic hierarchy process based on entropy weight," Fuzzy Sets and Systems, vol. 62, no. 2, pp. 127-134, 1994.

[49] J. Ye, "Multicriteria fuzzy decision-making method using entropy weights-based correlation coefficients of intervalvalued intuitionistic fuzzy sets," Applied Mathematical Modelling, vol. 34, no. 12, pp. 3864-3870, 2010. 


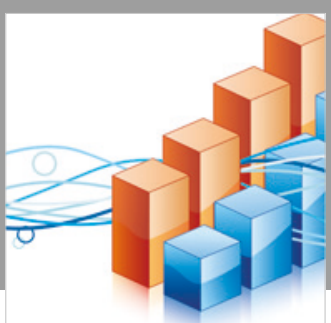

Advances in

Operations Research

\section{-n-m}
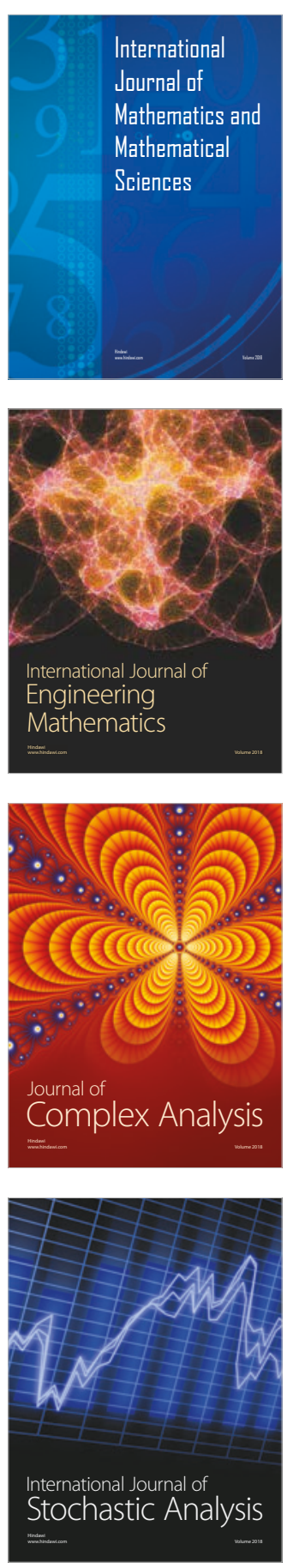
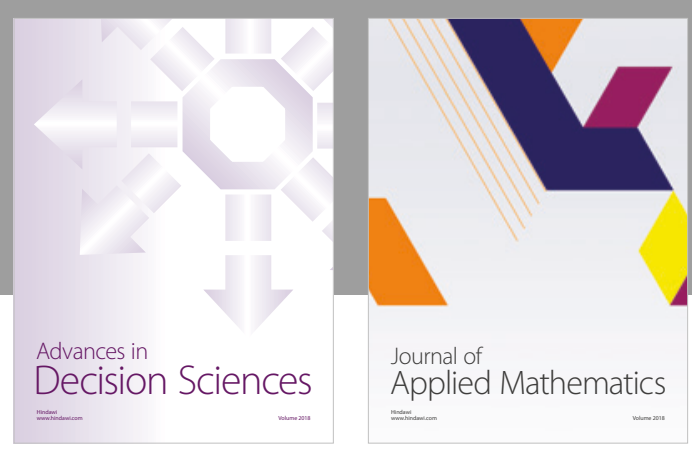

Journal of

Applied Mathematics
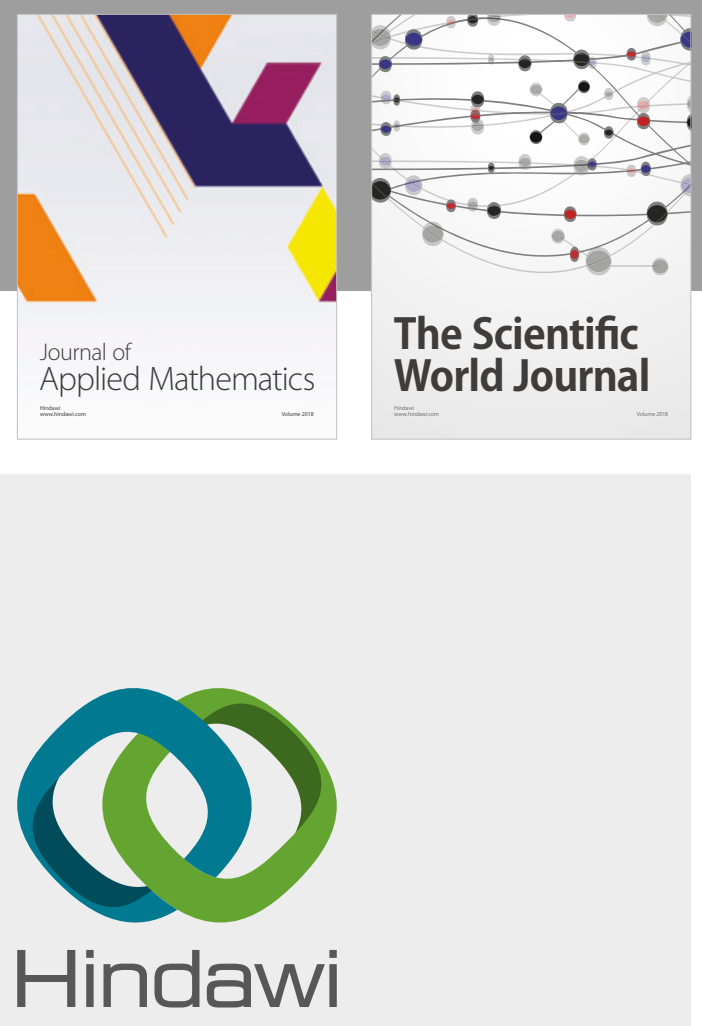

Submit your manuscripts at

www.hindawi.com

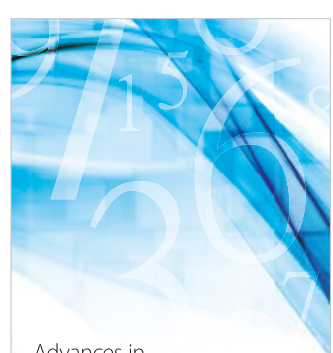

Advances in
Numerical Analysis
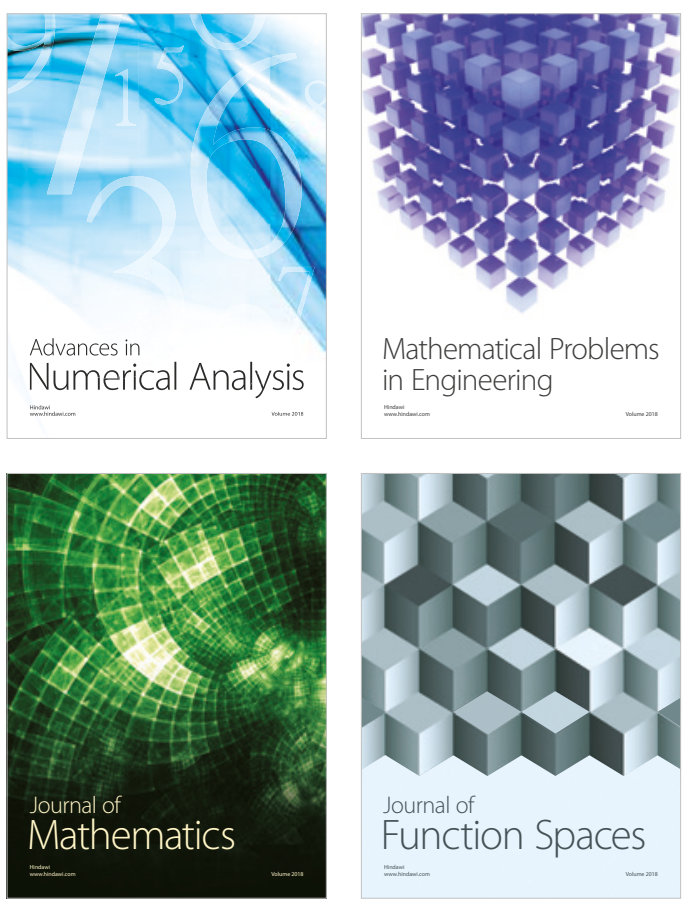

Mathematical Problems in Engineering

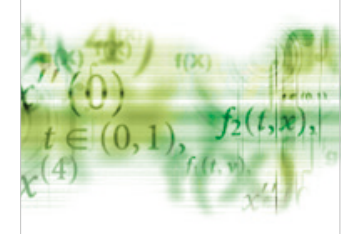

International Journal of

Differential Equations

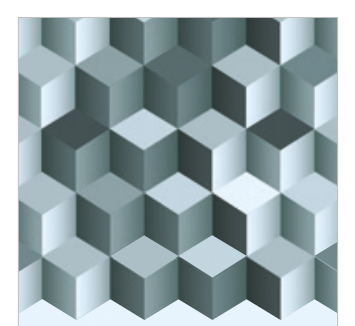

Journal of

Function Spaces

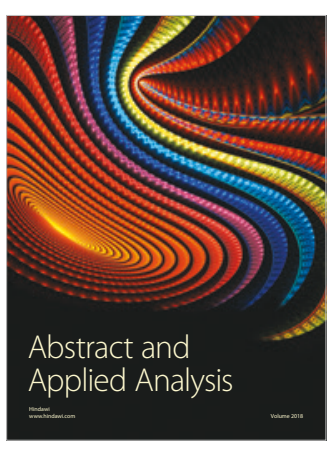

The Scientific

World Journal

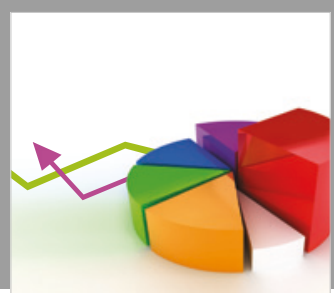

Journal of

Probability and Statistics
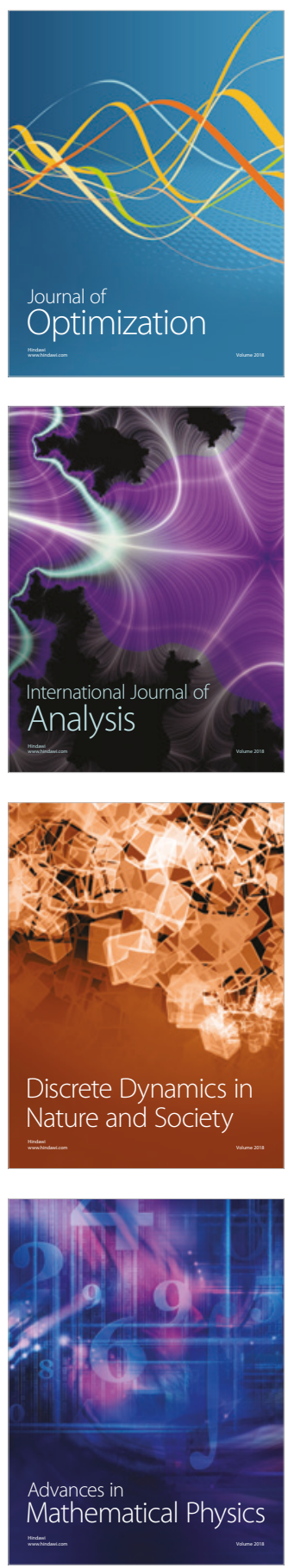